\title{
Knowledge Recycling and Transformation in Design
}

\author{
Buthayna Hasan Eilouti \\ Professor of Architecture, Prince Sultan University \\ Saudi Arabia
}

\section{Introduction}

In most design fields, many design processing activities are directly or indirectly information-driven and knowledge-based. However, major storage, retrieval and processing tasks that are usually associated with design knowledge management are redundantly repeated for each design assignment. In addition to management problems, there is a deficiency in knowledge networking where information in different areas are not sufficiently linked. In other words, in many cases, knowledge existing in one discipline can inform and inspire problem solving methods in others if represented properly.

This chapter introduces proposals of knowledge recycling and modeling where precedentbased prototypes can be reused to generate new designs. It also introduces an approach to knowledge transformation, where knowledge extracted in one discipline can inform innovative solutions in another. Both, knowledge recycling and transformation are argued to help eliminate redundant search for knowledge and aide in making knowledge base in one field more accessible and usable in another.

\section{Knowledge in design}

Knowledge is essential for design derivation in all processing phases: pre-design reasoning, design development and post-design evaluation, as well as in the linkage of all of these in recursive refinement cycles. Major tasks, especially in the pre-design phase, consist of basic prototypical ingredients such as component analysis, relational matrices, topological studies, zoning diagrams and sequential flow charts. Despite the common structure underlying their applications, many design-related knowledge-based activities are redundantly repeated in various design assignments. As such, recycling and transforming knowledge within and between disciplines become increasingly necessary to eliminate redundant repetitions and to facilitate accessing and applying previous knowledge to new designs. In this chapter, examples of knowledge recycling and transformation are demonstrated and discussed.

Within the scope of this chapter, knowledge management is studied in the context of engineering design. It includes methods for recycling, transformation, networking and modeling of the data underlying design processing tasks.

Research in design knowledge management is significant for design theory, practice and education. On the theoretical level, the study introduced in this chapter aims to reveal new 
models that form sources of inspiration for concept derivation and to help in the transformation of abstract knowledge constructs into applied design models.

On the practical level, when clear transformation and recycling methods and models are described, the applied knowledge developed from the abstract knowledge constructs can be implemented to derive more optimum processes and perhaps more innovative designs.

On the pedagogical level, this research may contribute to mapping complex problems to potential solutions through grouping combinations of sub-models to generate various alternative solutions; or through using existing models in other fields of study as points of departure for problem-solving in design. Each of the developed transformation and mapping methods may provide guidance with which designers and students can avoid the problem of repeating previous solutions and reach satisfactory design solutions with relative ease and speed. In addition, the generated hybrid and cross-disciplinary models are expected to contribute to the education of design through explicit and externalized templates. Knowledge recycling and transforming models aim to contribute to new systematic design derivation methods and to explore new sources of inspiration and innovation in design.

As an extension of this research, the applicable models and processes can be developed into computer aids that may assist designers generate their products more efficiently. These automated aids may be built as blocks and hyper-linked documents. They can also form a basis for a knowledge base for design problem solving and derivation.

\section{Knowledge recycling in design}

The scope of this research is limited to architectural design. Within this scope, building design generation can be considered the core and ultimate goal of knowledge cycle management. For the purpose of this study, the source of information in this cycle will be building precedents. As such, the knowledge cycle starts from data as embedded in precedent documented representations (see Figure 1). Upon interpretations of raw data and assignment of semantic attributes to them, data mutate into information. The latter, upon organizing and classifying its contents, can be transformed into abstract knowledge prototypes. These, in turn, subject to proper representation methods can be translated into applied knowledge models. Combined with informed design methodologies, the applied knowledge models can be implemented to produce new designs that may be documented to represent new precedents that, if communicated properly, may represent a new point of departure for future designs. The intention of design knowledge recycling models is to translate their contents into applied knowledge that can be transformed into new design products. They can be arranged in the pre-design phase of designing to embody chunks of knowledge as needed in order to interpolate their information to derive new alternatives. The proposed models are introduced and discussed in the knowledge modeling section that follows.

\section{Design knowledge processing}

In the context of engineering design in general, and in architectural design in specific, the most significant activities associated with knowledge management are:

1. Knowledge analysis

2. Knowledge organization

3. Knowledge modeling 
4. Knowledge derivation

5. Knowledge implementation

6. Knowledge communication

7. Knowledge documentation, and

8. Knowledge evaluation

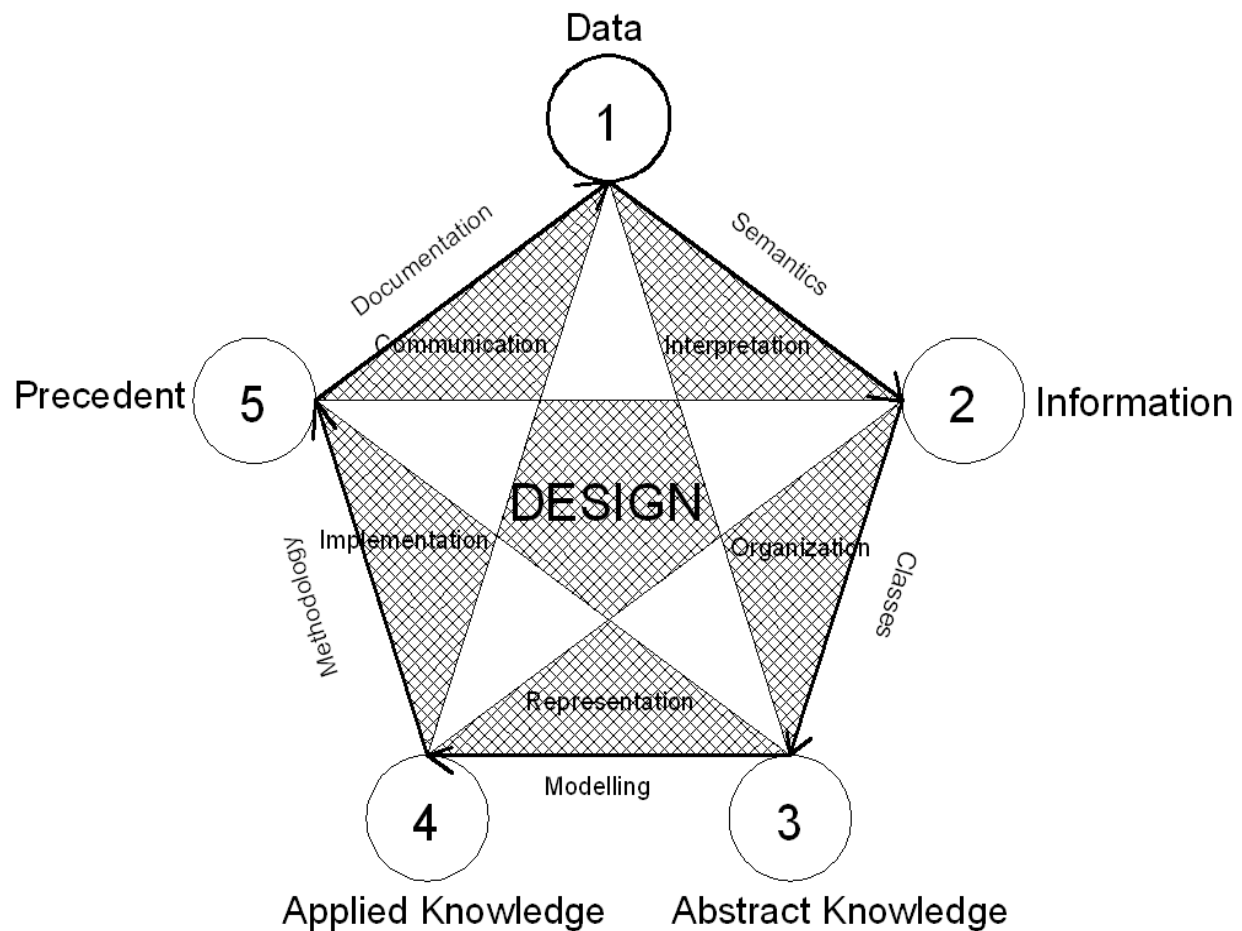

Fig. 1. Knowledge recycling pentagon

These eight design-related knowledge management areas are illustrated in Figure 2. They are represented as a knowledge management octagon where the transition from one station into the next requires additional layers of interpretation to clarify its premises and present its processing phases and resultant products. Some of these areas were emphasized in previous researches (Eilouti, 2007, 2009, 2011). However, the recycling octagon introduced in Eilouti, 2009 is revised here to fit the context of this chapter. In this revised octagon, the design knowledge processing sequence starts with design analysis, where knowledge from documented designs in previous case studies can be extracted, analyzed and assessed to prepare reusable parts for the generation of new knowledge. Upon its extraction, the analyzed design knowledge needs organization to categorize its contents based on predefined criteria and goals. Based on knowledge organization, it becomes possible to model knowledge either in easier to understand abstract models, or in easier to implement applied models. Knowledge is then represented in applicable models which, in turn, can be applied to produce new designs. This cycle from knowledge analysis to modeling uses layers and components of knowledge in an inductive reasoning approach to conclude wholes from 
parts. The next cycle departs from the knowledge-based implemented models. These need to be synthesized in the form of multiple alternatives of design proposals and filtered to develop design derivation. This sub-cycle represents the main core of the designing process; which is design development. The generated designs are then evaluated to test their weaknesses and strengths in order to revise any of the previous sub-cycles if necessary. The communicated representations need then to be documented for future reference. This subcycle from knowledge communication to knowledge evaluation encompasses post-design activities and mainly is concerned with re-presentation of produced designs in different formats, and with the study of the derivation and analysis processes. The design activities included in this cycle are mostly deductive and represent the pre-design phase of future designs. In this phase, design compositions are analyzed to be later assembled from the basic elements that are embedded in precedent-based generated knowledge. The two main areas of concern of this knowledge processing octagon in this research are the knowledge modeling, and knowledge recycling. This latter recursively loops between documented precedent-based design knowledge and generated product. These two knowledge areas- modeling and recycling- will be discussed in more detail in this section and the following sections.

The transition from each knowledge-related activity to the next in the management octagon requires a major task that is possibly associated with multiple minor ones. For example, the deductive cycle of the design recycling loop starts from studying previously documented designs, it requires reasoning to analyze existing knowledge. Upon analyzing its contents, precedent-based knowledge as embedded in case studies can be subject to critical assessment to evaluate what parts can be reused and how they function. Next, new knowledge can be inferred from evaluated previous experiences to generate new guidelines that may inform future designs. The main task needed for the transition from knowledge derivation to knowledge implementation is the organization of its associative data and information. This task requires classification and categorization of the relevant information. Similarly, a prototyping of organized data is required to prepare managed knowledge to be modelled in more usable formats in the next stage. This task uses typology and classification to help prototype given knowledge body in recognizable and reusable models. Then, these models need to be synthesized in many forms as a point of departure for the generation process. Upon modeling in more usable formats, knowledge-based prototypes require adopting a clear methodology to explain how they will be implemented to generate new products. When implemented, the product designs need to be presented in different formats including text, graphics, and mock ups to make them executable and comprehensible by other design parties. This requires visualization and representation methods. After proper communication of the design product, its associative knowledge requires archiving for future reference. The documented representations of designs take typically the form of archiving them as precedents or design cases.

\section{Knowledge modeling}

One of the major stations in the knowledge recycling pentagon (Figure 1) and in knowledge management octagon (Figure 2) represents knowledge modeling. In the first, it is represented as the transitional stage from abstract knowledge to applied one. In the second, it is represented directly as the design knowledge modeling station.

Within the framework of model structuring as illustrated in Figures 1 and 2, the main concern of this research is the development of applied models which can serve as both 


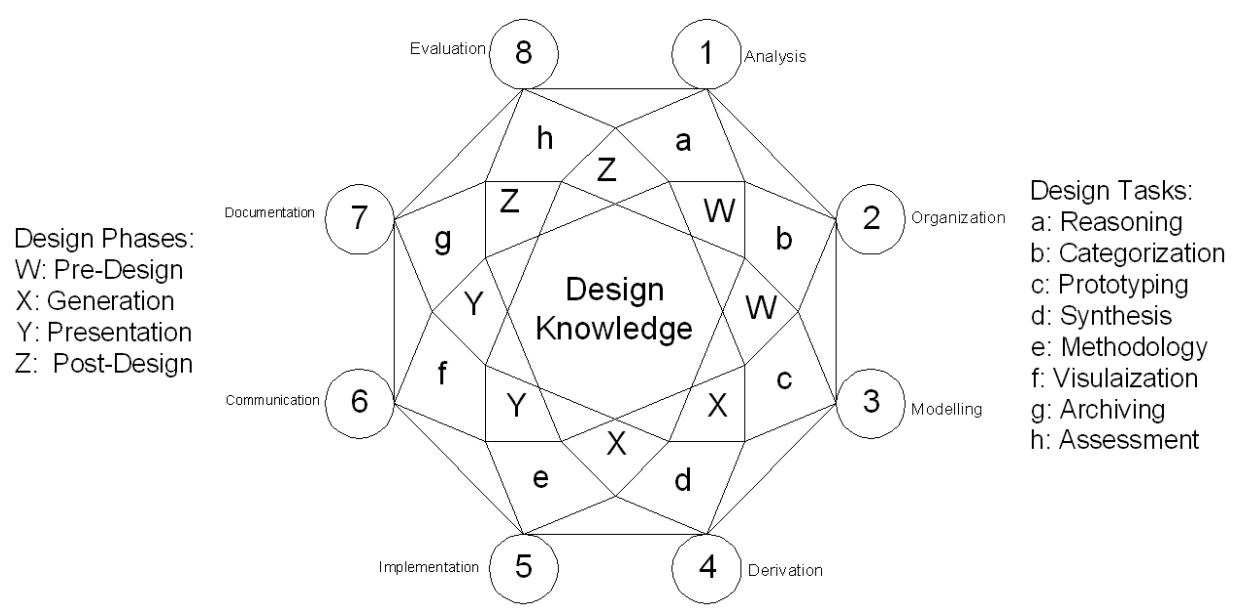

Fig. 2. Knowledge management octagon

analogical and metaphorical references, as well as inductive and deductive inference resources for design generation. The models are developed based on a study of related precedents and therefore called Precedent-Based Design (PBD ) models. The PBD models are classified into seven classes. These are:

1. Scenario-Based Models (SCBM)

2. Prototype-Based Models (PTBM)

3. System-Based Models (SYBM)

4. Concept-Based Models (CNBM)

5. Component-Based Models (CMBM)

6. Principle-Based Models (PRBM)

7. Rule-Based Models (RLBM)

All of these models are based on studying examples of existing precedents and analyzing them according to either retrospective or prospective approaches. In the retrospective approach, a designer starts with a given design problem and analyzes precedents that are relevant to it. In the prospective approach, a designer synthesizes existing PBD models into multiple alternatives and develops one of them based on continuous evaluation and generation cycles. Reasoning with one of the PBD models depends on the features of emphasis it details. Classification of the models is based on the type of data extracted from precedents, and on the way the extracted data is expected to be implemented and manipulated. The seven models are illustrated in Figure 3.

Precedents in each model are analyzed to conclude a group of interrelated properties that can be assembled in a layer of coherent data. As such, similar functions are assembled in separate layers as a mechanism for the classification of data in terms of predefined criteria and goals. Such a classification enables users to hide or exclude data temporarily from the design as needed. In addition, this classification facilitates searching of entities of more interest to users and isolating them as the design processing phase requires. The seven models and their associated layers of information include:

1. The first type is the Component-Based Model (CMBM). In this type, a layer may represent a set of homogeneous components that belong to one category, such as the vocabulary elements that correspond to the functional components of a building program such as classrooms, 
meeting halls and exhibition spaces. A layer may also consist of a designer's toolkit that may summarize design key goals, constraints, methods, strategies or techniques; reasoning or synthesis methods of a design; and tools of representation and media employment. A layer may emphasize and isolate building blocks such as the sets of roofs, windows, walls and masses used in design. Furthermore, a layer may highlight the patterns of functional clustering such as those described by Alexander's patterns (Alexander, 1977), which are based on resolving conflicts that may result from behavioral tendencies of grouping different building spaces.

2. The second type is the Principle-Based Model (PRBM). In this model, principles of form composition are deduced from a morphological analysis of the structures of studied precedents. They include visual and aesthetic principles such as rhythm, symmetry, proportion, scale, balance, integration, unity, character, and part-to-whole or void-to-solid ratios. The principles also include those that highlight the codes and regulations such as the ones used to control barrier-free or emergency exit regulation compliance that are concluded from precedents and formulated to define and restrict new designs. In addition, they include pre-defined standards that are typically used to guide the generation of an aesthetic design, such as the golden section proportional system, the ergonomic quality assurance requirements and the optimum sizes of functional spaces that can be found in architectural and engineering standardization references.

3. The third type represents Rule-Based Model (RLBM), in which the syntactic rules underlying the derivation of precedent designs are inferred. These are then represented either in the form of relational rules or process-related rules. In the first, rules emphasize the morphological structure of a composition and how components are topologically and mathematically related in space. In the second, rules are concluded to guide the incremental evolution sequence that emphasizes the procedural aspects of form making and the steps and phases of producing the final product. Both types of rules (relational and procedural) are represented in shape grammars. So, a shape grammar of precedents can propose guidelines about the morphological structure and designing process for future similar designs. As examples of shape grammar studies see Eilouti et. al.(2007, 2009).

4. The fourth type is Scenario-Based Model (SCBM). A precedent in this type is portrayed in its entirety for performance evaluation purposes. The functionality of a case may be investigated in different situations and for different purposes. A what-if game can be played to test different aspects of a case performance. As such, a particular behavioral aspect can be simulated in a precedent. For example, a precedent may be tested to check how it may function from the viewpoint of potential users; that is a user-based analysis. User-based simulation of space utilization aims to study pedestrian movement patterns and space flow and accessibility. Consequently, the user-based scenario simulation findings can be used as input for future design decisions. A precedent can also be evaluated against a hypothetical event that may occur daily, weekly, monthly or yearly; that is an event-based analysis. In event-based performance simulation, the building at hand is investigated for its performance satisfaction of a pre-defined criterion such as escape routing, emergency exits, or its comfort assurance and compliance in response to directed tests such as those related to lighting, airflow, acoustics, and visual and thermal comfort.

5. As in the previous type, each case in a Prototype-Based Model (PTBM) is portrayed in its entirety. A set of attributes in precedent designs is captured in its holistic character to be transformed into future designs. Its transformation entails its adaptation to generate another solution. In this model, a design template or a prototype can be inferred from a precedent to serve as a point of departure for relevant new designs. A prototypical model may be developed based on the functional components of precedents, or their formal aspects. For example, spaces 
of a hospital could be clustered according to a given functional template as concluded from previous successful hospital designs. Similarly, a specific shape in plan may work well for many existing hospitals, which proposes a formal template for future hospital plans.

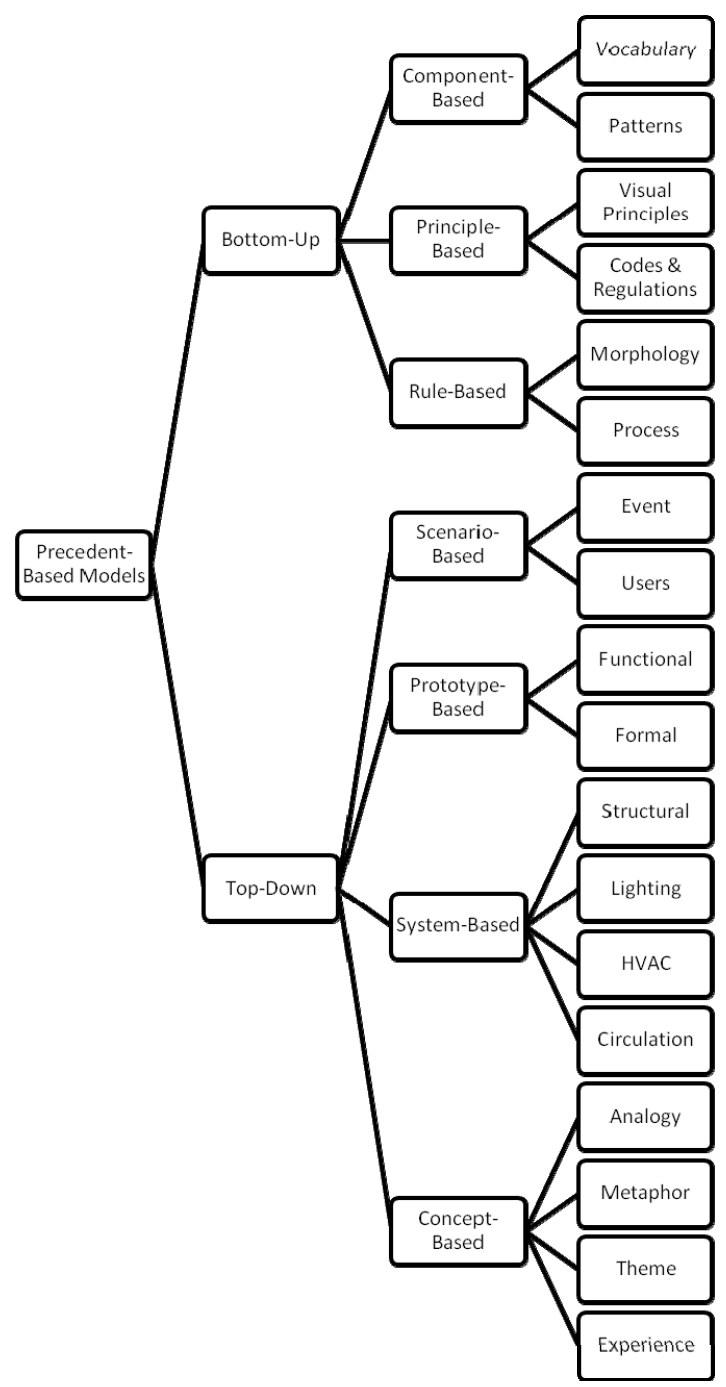

Fig. 3. The seven precedent-based models

6. Similar to the fourth and fifth types, a System-Based Model (SYBM) highlights a precedent as a whole. SYBM is based on the inference of systems in each of which a class of similar functional or formal elements is grouped. Possible systems that can be emphasized in a set of precedents include: structural, circulation, signage, HVAC and lighting systems.

7. In the previous models, most of the layers discussed so far are tangible. However, other intangible layers can be identified in them. The intangible layers are intensively represented in 
the conceptual model defined as Concept-Based Model (CNBM). This model encompasses the philosophical, semantic and symbolic aspects underlying a precedent design. Within this model, the design philosophy of the precedent case at hand can be concluded, or a possible analogy, metaphor, scheme or theme can be drawn from it. In CNBM, the significant factors that may enhance creativity and imagination in a precedent are explored. For example, a theme or a story can be tailored from its composition. Similarly, an aspectual analogy can be drawn from comparing physical elements of a precedent with other known products or creatures. Or, some semantic layers can be borrowed in a metaphorical reference. In CNBM, an attempt can be made to capture the spirit of a designer's style of designing. A future design based on CNBM may cast the internal stylistic spirit on a new design that the same designer could hypothetically produce in different temporal or contextual settings.

\section{Knowledge transformation}

This section demonstrates an example of knowledge transformation. Such a transformation is represented by Biomimetics, where solutions offered by natural organisms are studied to inform innovative design problem solving in engineering applications. In this context, Biomimetics represents a transformation of environmental knowledge into engineering design. As such, it links knowledge learned from nature to concepts of man-made product generation. The epistemological and methodological assumptions underlying knowledge transformation in Biomimetics are based on a cross-disciplinary understanding and approach to knowledge building. In this approach, knowledge is transformed from biology to other design-oriented disciplines such as engineering. As a result of knowledge networking, natural organisms and man-made products are mapped to draw some solutions from the former to inform the latter. Upon mapping, nature can be imitated directly as a template or indirectly as a metaphor to solve design problems. Such mapping is referred to as Biomimicry. The "Biomimicry" term represents a concatenation of "bio" which means life and "mimesis" meaning imitation. In its study of nature, biomimicry analyzes living organisms for their shapes, models, behaviors, systems, morphologies, anatomies, components, topologies and processes as well as their fitting in their communities and natural environments. The study then uses analogical or metaphorical reasoning to imitate or take creative inspiration from them to derive sustainable and optimal solutions for human design problems.

Based on biomimicry, Biomimetics -or biologically-inspired technological application- is most frequently used in scientific and engineering literature to indicate the process of applying biological principles that underlie the morphology, structures and functionality of biological entities to manmade designs (Benyus, 1997). In this process, natural organisms are investigated to extract solutions from their adaptation techniques to their environments. Consequently, new concepts may be derived through partial or holistic extrapolation from natural solutions to artificial ones.

Scholarly works and research projects in the areas of Biomimicry and Biomimetics and their applications in engineering design are relatively new and increasingly growing (Reap et. al., 2005; Rosemond and Anderson, 2003; Todd, 2004; Wainwright et. al., 1976). Examples of Biomimetics applications include spidersilk that is used as building material, and fuel cells that power automobiles and release water instead of carbon dioxide.

While engineering applications of Biomimetics are increasingly growing, a much slower rate of knowledge networking between Biomimetics and architectural design is witnessed. 
Although some examples exist in architecture (Berkebile and McLennan, 2004; Hansell, 2005; Knowles, 2006; Feuerstein, 2002) and mostly on the urban/environmental level (Hastrich, 2006; Kibert, 2006; Pedersen and Storey, 2007); using Biomimetics as a point of departure to approach architectural design in ways other than formal analogy is still under researched. In the following section, a biomimetics-based design approach is proposed. The approach is discussed, developed and implemented as a project in a real design studio to test its applicability. The approach that is summarized in the following sections is further detailed in a separate research (Eilouti, 2010).

\section{Biomimetic approach to design}

A proposal for a new biomimetics-based design approach is represented as an exercise on inter-disciplinary knowledge networking. The exercise aims to develop new formal and functional treatments that evolve from contextual fit considerations and users' changing needs as well as product lifecycle factors. In this exercise, the inter-disciplinary knowledge transfer and deployment is preceded by a cross-disciplinary development of a new approach to architectural designing that shifts conventional paradigms of design thinking, which are mostly centered about formal attributes, into behavior-centered and function-oriented design formations. As such, the approach proposed in this study is concerned with the development of design solutions from the context and environment of a designated design not only to generate organic forms but also to develop environment-friendly functions, systems and solutions.

The approach uses new resources of inspiration that are simulated by digital studio tools. It is described, implemented, reflected on and discussed in digital design studio settings for third year architectural engineering students in Jordan University of Science and Technology (JUST). The approach is presented to introduce a new style in architecture, which we called "BioTecture". It is represented as a Biomimetic-Inspired Design (BID) project and is based on the application of principles of biomimetics on architectural design using various points of departure. All departure paths map buildings to living creatures, but vary in order of station points. The approach includes three methods (Figure 4). These are:

1. Building-Based Design (BBD),

2. Organism-Based Design (OBD) and

3. Application-Based Design (ABD).

\subsection{Building-based design method}

In this method, a designer starts from the building that needs designing. For its design, s/he:

1. Defines a specific design problem

2. Finds an organism in a specific biome that exhibits a partial or total solution to the problem defined in the first step. This search may include more than one organism that shares various aspects with the subject of designated design problem and a biome that shares some aspects with the design context or environment

3. Extracts information from the selected organisms and biomes as needed

4. Maps the extracted information to the design problem

5. Develops a design solution or proposes potential alternatives from the match between the information and building aspects

6. Evaluates the design product using criteria from the original organisms and biomes that are used for inspiration or imitation 


\subsection{Organism-based design method}

In the organism-based method, a designer studies an organism and its relationships to its biome, and then draws partial solutions from the analysis. In this method, a designer:

1. Identifies an organism the features of which seem inspiring for a design solution

2. Extracts detailed information about the organism

3. Defines a design problem that seems relevant to the features defined in the first step and the information extracted in the second

4. Maps the extracted information to the design problem

5. Develops a design solution or proposes potential alternatives from the match between the information and building aspects

6. Evaluates the design product using criteria from the original organisms and biomes that are used for inspiration or imitation

\subsection{Application-based design method}

In the application-based method, a designer starts from an application that is inspired by organisms or natural systems and draws parallels between that application and buildings or design problems that share some aspects with it. In this method, a designer:

1. Finds an application that offers promising solutions to architectural design problems

2. Defines a design problem that seems relevant to the application identified in the first step

3. Extracts detailed information about the application and the solutions embedded in its design including the original organisms/biomes that inspired the application

4. Extrapolates the extracted information to the design problem

5. Develops a design solution from the match between the application aspects and the building desired attributes

6. Evaluates the design product using criteria from the application's successful accomplishments and from the original organisms that are used for inspiration or imitation

\section{BioTecture project}

Based on the above described approach, a biomimetics-inspired design (BID) project was assigned to the JUST students. It is mainly concerned with the design of a self-sufficient adaptive house that changes its structures and configurations according to inhabitants' needs. The house is also supposed to respond to climatic changes, and to mutate in form and spatial organization during its lifecycle. Since the project views a building as a living creature that continuously changes in response to internal and external factors, and since it is inspired by living creatures, the project's style is called "Biotecture".

Reflections and feedback about the approach and the project implementation are measured by structured questionnaire. The questionnaire was given to the students who worked on the project after they finished the term in which they were assigned the project (Eilouti, 2010) to guarantee neutral feedback.

The results of the project implementation seem to encourage adopting its associative environmental problem-solving techniques and inter-disciplinary approaches as complementary for conventional functional- or formal-oriented problem-solving approaches as points of departure for design generation. However, the new design approach has some limitations as its participants pointed out. One of these is that it limits expressing the designer's personality in the generated design. 


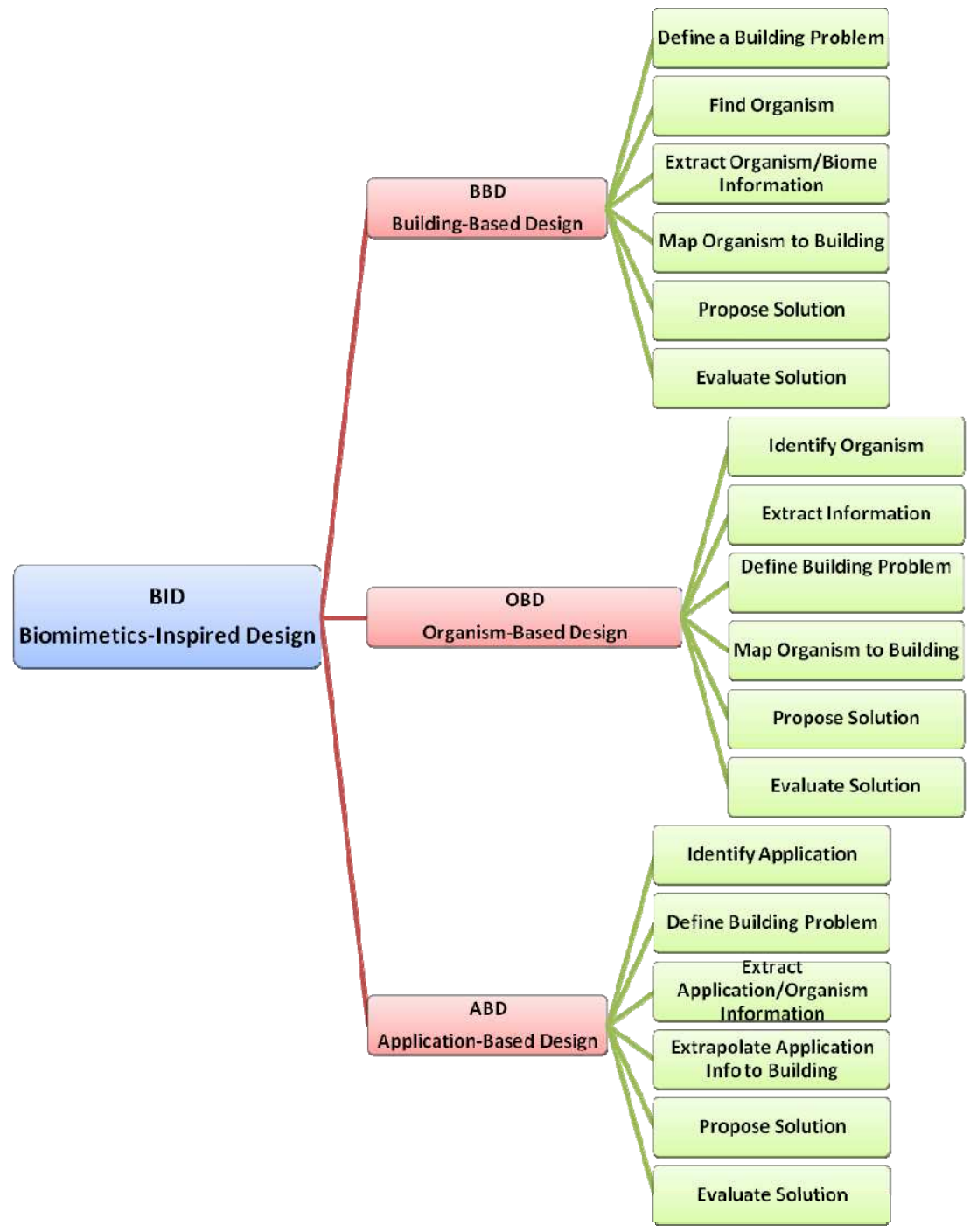

Fig. 4. The biomimetics-inspired design methods

Future extensions of this line of research include the automation of databases that are relevant to biosystems and that may be matched to artificial artifacts through computer-aided software. Such software may help in the external and internal referencing between entities and in the knowledge linkage and networking between databases in different disciplines.

\section{Conclusion}

Given that knowledge is essential for most design tasks, it can be made more accessible, applicable and useful if approached and represented in new forms. It can be recycled by 
analyzing relevant design precedents and re-synthesized to derive new emergent solutions. These are represented in this chapter as seven precedent-based design recycling models. Knowledge can also be made more useful if transformed from one discipline into another. This is shown in this chapter as biomimetics-inspired design (BID) approach to architectural design. In all of these knowledge management methods including recycling, modeling and transformation; problem-solving can be made more externalized, informed and systematic. Furthermore, applying these methods may provide new sources not only for learning but also for innovation.

\section{References}

Alexander, C. (1977). A Pattern Language: Towns, Buildings, Construction. Oxford University Press Benyus, J. (1997), Biomimicry: Innovation inspired by Nature. New York: William Morrow.

Berkebile, B. and McLennan, J. (2004), The living building: biomimicry in architecture, integrating technology with nature. BioInspire 18.

Eilouti, B (2007) Models for the Management of Precedent-Based Information in Engineering Design, pp. 326-331, the 11th World Multi-Conference on Systemics, Cybernetics and Informatics, USA

Eilouti, B. and A. Al-Jokhadar. 2007. A Generative System for Mamluk Madrasa FormMaking, Nexus Network Journal Vol 9, No.1, pp. 7-30, Birkhäuser, Basel, Switzerland

Eilouti, Buthayna H., Al-Sha'ar, Jamil, 2012, Shape Grammars of Traditional Damascene Houses, International Journal of Architectural Heritage, Vol 6 (4), Taylor \& Francis, pp. 1-21, UK

Eilouti, B.H. (2009), Design knowledge recycling using precedent-based analysis and synthesis models, Design Studies, Elsevier Vol 30, No.4, pp. 340-368

Eilouti, B. H. (2010), Biomimetically Correct, International Journal of Architectural Research , Archnet, MIT Press, Vol 4, 2/3 USA, pp 429-442

Eilouti, B. H. (2011), Environmental Knowledge in Engineering Design Processing, The 5th International Conference on Knowledge Generation, Communication and Management: KGCM 2011, Orlando, Florida, USA, pp 370-375

Feuerstein, G. (2002), Biomorphic Architecture - Human and Animal Forms in Architecture, Stuttgart, Edition Axel Menges.

Hansell, M. (2005), Animal Architecture, New York, Oxford University Press.

Hastrich, C. (2006), The Biomimicry design spiral, Biomimicry Newsletter, 4.1, p. 5-6.

Kibert, C. J. (2006), Revisiting and reorienting ecological design. Construction Ecology Symposium. Massachusetts Institute of Technology, Cambridge, MA.

Knowles, R. (2006), Ritual House: Drawing on nature's rhythms for architecture and urban design. Island Press.

Pedersen Zari, M. and Storey, J. B. (2007), An ecosystem based biomimetic theory for a regenerative built environment. Lisbon Sustainable Building Conference 07. Lisbon, Portugal.

Reap, J., Baumeister, D. and Bras, B. Holism (2005), biomimicry and sustainable engineering. ASME International Mechanical Engineering Conference and Exposition. Orlando, FL, USA.

Rosemond, A. D. and Anderson, C. B. (2003), Engineering Role Models: Do Non-Human Species have the Answers? Ecological Engineering, 20, p. 379-387.

Todd, J. (2004), Restorer eco-machines for the culture of aquatic animals and the restoration of polluted aquatic environments. BioInspire 19.

Wainwright, S. A. (1976), Biggs,W. D., Currey, J. D., Gosline,J. M., Mechanical Design in Organisms, New York, Wiley. 


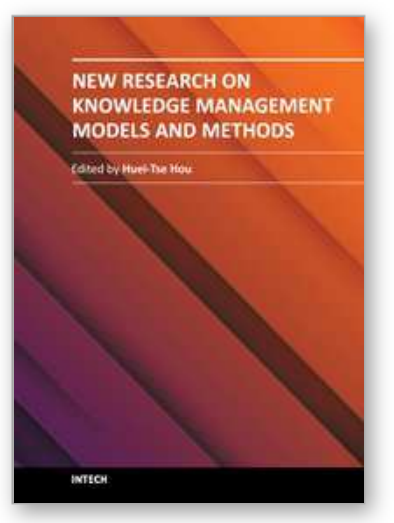

\author{
New Research on Knowledge Management Models and Methods \\ Edited by Prof. Huei Tse Hou
}

ISBN 978-953-51-0190-1

Hard cover, 426 pages

Publisher InTech

Published online 23, March, 2012

Published in print edition March, 2012

Due to the development of mobile and Web 2.0 technology, knowledge transfer, storage and retrieval have become much more rapid. In recent years, there have been more and more new and interesting findings in the research field of knowledge management. This book aims to introduce readers to the recent research topics, it is titled "New Research on Knowledge Management Models and Methods" and includes 19 chapters. Its focus is on the exploration of methods and models, covering the innovations of all knowledge management models and methods as well as deeper discussion. It is expected that this book provides relevant information about new research trends in comprehensive and novel knowledge management studies, and that it serves as an important resource for researchers, teachers and students, and for the development of practices in the knowledge management field.

\title{
How to reference
}

In order to correctly reference this scholarly work, feel free to copy and paste the following:

Buthayna Hasan Eilouti (2012). Knowledge Recycling and Transformation in Design, New Research on Knowledge Management Models and Methods, Prof. Huei Tse Hou (Ed.), ISBN: 978-953-51-0190-1, InTech, Available from: http://www.intechopen.com/books/new-research-on-knowledge-management-models-andmethods/inter-disciplinary-knowledge-recycling-and-transformation

\section{INTECH}

open science | open minds

\author{
InTech Europe \\ University Campus STeP Ri \\ Slavka Krautzeka 83/A \\ 51000 Rijeka, Croatia \\ Phone: +385 (51) 770447 \\ Fax: +385 (51) 686166 \\ www.intechopen.com
}

\author{
InTech China \\ Unit 405, Office Block, Hotel Equatorial Shanghai \\ No.65, Yan An Road (West), Shanghai, 200040, China \\ 中国上海市延安西路65号上海国际贵都大饭店办公楼 405 单元 \\ Phone: +86-21-62489820 \\ Fax: $+86-21-62489821$
}


(C) 2012 The Author(s). Licensee IntechOpen. This is an open access article distributed under the terms of the Creative Commons Attribution 3.0 License, which permits unrestricted use, distribution, and reproduction in any medium, provided the original work is properly cited. 